\title{
Reseña de la jurisprudencia de la Corte Interamericana de Derechos Humanos (2009)
}

Este comentario, junto a los documentos que analiza, está disponible en www.anuariocdh.uchile.cl

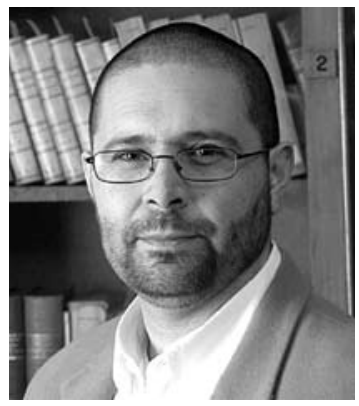

\section{Claudio Nash Rojas}

Licenciado en Ciencias Jurídicas y Sociales (Universidad de Chile, 1998) y Doctor en Derecho (Universidad de Chile, 2008). Coordinador Académico del Centro de Derechos Humanos de la Facultad de Derecho de la Universidad de Chile y Director del Programa "Estado de Derecho y Derechos Humanos" del mismo Centro. cnash@derecho.uchile.cl

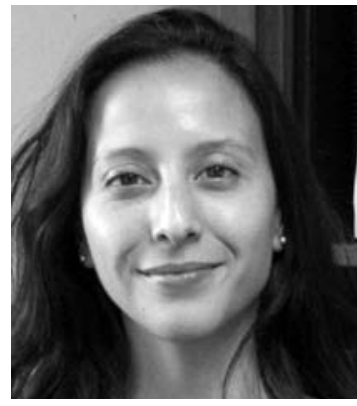

\section{Claudia Sarmiento Ramírez}

Licenciada en Ciencias Jurídicas y Sociales de la Universidad de Chile, de la Facultad de Derecho de la Universidad de Chile. Investigadora del Programa "Mujeres y Derechos Humanos" y editora del Anuario de Derechos Humanos, del Centro de Derechos Humanos (CDH) de la misma Casa de Estudios.

csarmien@derecho.uchile.cl

\section{RESUMEN}

El artículo revisa críticamente las sentencias dictadas por la Corte Interamericana de Derechos Humanos durante el año 2009 que, a juicio de los autores, serán relevantes para la región. A partir del análisis de las sentencias se examina, por una parte, el tema de la violencia contra las mujeres y derechos humanos; y por otra, revisitaremos el tema de los alcances de la obligación de garantía. Igualmente se analizan sentencias que marcarán tendencias en el sistema respecto del derecho a la vida, debido proceso, en particular en el tema de la independencia judicial, derechos políticos y derechos económicos, sociales y culturales.

La Corte Interamericana de Derechos Humanos ("Corte" o "Corte Interamericana") fue establecida en el sistema interamericano por la Convención Americana sobre Derechos Humanos ("CADH" o "Convención Americana") ${ }^{1}$. Sus funciones son dos: (a) resolver los casos contenciosos sobre

1 La Convención Americana sobre Derechos Humanos se adoptó en 1969 durante la Conferencia Especializada de Derechos Humanos, realizada en San José, Costa Rica. 
una presunta violación a la Convención Americana de un Estado Parte, y (b) emitir opiniones consultivas.

Conforme con lo preceptuado en el artículo 63 de la CADH, la Corte establecerá si ha habido una violación de alguno de los derechos o libertades consagrados en la Convención Americana. Además, determinará la forma en que el Estado debe restituir la situación al estado anterior a la comisión del ilícito y, en caso de que esto no sea posible, determinará la manera en que se reparará el mal causado. Conforme con lo dispuesto en el artículo 68.1 de la Convención Americana, las partes se comprometen a cumplir las decisiones de la Corte.

Durante el año 2009 la Corte dictó 15 sentencias definitivas y una opinión consultiva.

En este artículo reseñaremos algunas de las sentencias definitivas dictadas por la Corte que pueden ser de relevancia para nuestra región. Nos referiremos a dos aspectos generales que surgen de la jurisprudencia de este año: por una parte, el tema de la violencia contra las mujeres y derechos humanos; y por otra, revisitaremos el tema de los alcances de la obligación de garantía. En la segunda parte, analizaremos algunas sentencias que marcarán tendencias en el sistema respecto del derecho a la vida, debido proceso, en particular en el tema de la independencia judicial, derechos políticos y derechos económicos, sociales y culturales.

\section{Aspectos generales}

\section{a. Mujeres y discriminación}

La violencia es un complejo fenómeno social que afecta a muchas mujeres en América Latina ${ }^{2}$, y que guarda estrecha relación con los estereotipos sobre el rol que tradicionalmente se espera jueguen en la sociedad ${ }^{3}$. En los últimos 20 años se ha instalado un discurso público que rechaza la violencia contra las mujeres, el cual ha conducido a la modificación de la legislación -tanto penal como civil- de muchos países del continente ${ }^{4}$. Un ejemplo de ello es que América Latina es el único continente que cuenta con una convención que aborda exclusivamente la violencia contra las mujeres: la Convención Interamericana para Prevenir, Sancionar y Erradicar la Violencia contra la mujer, "Convención de Belém do Pará", de 1994. No obstante, a pesar de los avances a nivel formal en la erradicación de la violencia contra las mujeres, las cifras de violencia en la región continúan siendo altas, así como las críticas a la actuación del Estado en la prevención y sanción de ésta por parte de los tribunales ${ }^{5}$.

2 "Si tomáramos 10 mujeres representativas, mayores de 15 años, en cada país de América Latina y el Caribe, veríamos que cuatro peruanas y cuatro nicaragüenses sufren violencia física por sus esposos; en México, tres mujeres serían víctimas de violencia emocional y dos de violencia económica; tres brasileñas de violencia física extrema y dos haitianas de violencia física. Entre 1990 y 2007, más de 900 mujeres chilenas fallecieron por causa de homicidio, una gran mayoría víctimas de sus parejas o ex parejas". MONTAÑO, Sonia (coord.) ¡Ni una más! El derecho a vivir una vida libre de violencia en América Latina y el Caribe. Capítulo II. Las cifras de la violencia. CEPAL. Octubre 2007, pp. 26-75 Párr.

3 SEGATO, Rita. Las estructuras elementales de la violencia: contrato y estatus en la etiología de la violencia. Conferencia leída el 30 de junio de 2003 en la apertura del curso de verano sobre violencia de género dirigido por el Magistrado Baltasar Garzón de la Audiencia Nacional de España en la sede de San Lorenzo del Escorial de la Universidad Complutense de Madrid.

4 ALMÉRAS, Diane et al. Violencia contra la mujer en relación de pareja: América Latina y el Caribe, una propuesta para medir su magnitud y evolución. CEPAL. Unidad Mujer y Desarrollo. Proyecto Interagencial "Uso de Indicadores de Género para la Formulación de Políticas Públicas". Serie mujer y desarrollo, 40. Santiago de Chile, junio de 2002.

5 Comisión Interamericana de Derechos Humanos. Acceso a la Justicia para las Mujeres Víctimas de la Violencia en Las Américas. OEA/Ser L./V/II. Doc. 68, 20 de enero de 2007. 
El trabajo de la Corte Interamericana de Derechos Humanos no ha estado exento de esta crítica ${ }^{6}$. En una región donde la violencia es un fenómeno tristemente extendido, no fue sino hasta el "Caso del Penal Miguel Castro Castro"7 del año 2006, donde la Corte trató en forma explícita la violencia contra las mujeres como la manifestación más brutal de la discriminación que padecen. Ciertamente, las sentencias en los casos de "González y otras ('Campo Algodonero') Vs. México" 8 y de la "De la Masacre de las Dos Erres Vs. Guatemala" ${ }^{9}$, constituyen un avance significativo, no sólo por su efecto simbólico para las víctimas y la región, sino por los estándares que fija para los Estados en la erradicación, prevención y sanción de la violencia contra las mujeres.

La Corte empleó un criterio cualitativo para resolver cuándo existe violencia contra la mujer, pues declara que "no toda violación de un derecho humano cometida en perjuicio de una mujer conlleva necesariamente una violación de las disposiciones de la Convención de Belém do Pará"10. Utilizando la definición de violencia contra la mujer del artículo $1^{\circ}$ de la Convención Belém do Pará, indicó que ésta consiste en "cualquier acción o conducta, basada en su género, que cause muerte, daño o sufrimiento físico, sexual o psicológico a la mujer, tanto en el ámbito público como en el privado" ${ }^{\prime 1}$. En este criterio se basó para desestimar la aplicación de la Convención Belém do Pará en el "Caso Perozo y otros Vs. Venezuela":

“296. [...][L]os representantes no especificaron las razones y el modo en que el Estado incurrió en una conducta 'dirigida o planificada' hacia las presuntas víctimas mujeres, ni explicaron en qué medida los hechos probados en que aquéllas fueron afectadas 'resultaron agravados por su condición de mujer'. Los representantes tampoco especificaron cuáles hechos y en qué forma representan agresiones que 'afectaron a las mujeres de manera desproporcional'”.

En el caso de Campo Algodonero la Corte estableció que la desaparición y ulterior muerte de las jóvenes respondía a un patrón sistemático de violencia contra las mujeres en Ciudad Juárez ${ }^{12}$. Este era un antecedente relevante, pues si bien no estaba acreditado en el caso que existiese intervención directa de agentes del Estado, la Corte debía establecer si éste cumplió con la obligación de garantizar, es decir, si "previno adecuadamente la desaparición, vejámenes y muerte sufridas por las tres víctimas y si investigó las mismas con debida diligencia"13. La Corte estableció la responsabilidad internacional del Estado de México por la violación de "los derechos a la vida, integridad personal y libertad personal reconocidos en los artículos 4.1, 5.1, 5.2 y 7.1 de la Convención Americana, en relación con la obligación general de garantía contemplada en el artículo 1.1 y la obligación de adoptar disposiciones de derecho interno contemplada en el

6 PALACIOS, Patricia. The Path to Gender Justice in the Inter-American Court of Human Rights. Texas Journal of Women and the Law, 17(2), primavera 2008.

7 Caso del Penal Miguel Castro Castro Vs. Perú. Fondo, Reparaciones y Costas. Sentencia de 25 de noviembre de 2006. Serie C No. 160.

8 Corte IDH. Caso González y otras ("Campo Algodonero") Vs. México. Excepción Preliminar, Fondo, Reparaciones y Costas. Sentencia de 16 de noviembre de 2009. Serie C No. 205. El caso trata sobre la desaparición y muerte de las jóvenes Claudia Ivette González, Esmeralda Herrera Monreal y Laura Berenice Ramos Monárrez, cuyos cuerpos fueron encontrados en un campo algodonero de Ciudad Juárez el día 6 de noviembre de 2001.

9 Corte IDH. Caso de la Masacre de las Dos Erres Vs. Guatemala. Excepción Preliminar, Fondo, Reparaciones y Costas. Sentencia de 24 de noviembre de 2009. Serie C No. 211. El caso trata sobre la falta de debida diligencia en la investigación, juzgamiento y sanción de los responsables de la masacre de 251 habitantes del Parcelamiento de las Dos Erres, la Libertad, Departamento de Petén, ocurrida entre los días 6 a 8 de diciembre de 1982.

10 Caso Perozo y otros Vs. Venezuela. Párr. 295.

11 Artículo 1. Caso González y otras ("Campo Algodonero") Vs. México. Párrs. 225-231; Caso de la Masacre de las Dos Erres Vs. Guatemala. Párrs. 140 y 141.

12 Ídem. Párrs. 164, 231.

13 Ídem. Párr. 248. Énfasis en el texto original. 
artículo 2 de la misma, así como con las obligaciones contempladas en el artículo 7.b y 7.c de la Convención de Belém do Pará"14.

Al analizar cuál era el estándar de debida diligencia señaló que:

"258. [...][L]os Estados deben adoptar medidas integrales para cumplir con la debida diligencia en casos de violencia contra las mujeres. En particular, deben contar con un adecuado marco jurídico de protección, con una aplicación efectiva del mismo y con políticas de prevención y prácticas que permitan actuar de una manera eficaz ante las denuncias. La estrategia de prevención debe ser integral, es decir, debe prevenir los factores de riesgo y a la vez fortalecer las instituciones para que puedan proporcionar una respuesta efectiva a los casos de violencia contra la mujer. Asimismo, los Estados deben adoptar medidas preventivas en casos específicos en los que es evidente que determinadas mujeres y niñas pueden ser víctimas de violencia. Todo esto debe tomar en cuenta que en casos de violencia contra la mujer, los Estados tienen, además de las obligaciones genéricas contenidas en la Convención Americana, una obligación reforzada a partir de la Convención de Belém do Pará".

La Corte analizó las medidas que el Estado adoptó para cumplir con su obligación de garantizar, específicamente, con su deber de prevención ${ }^{15}$. Al efecto señaló que el Estado no responde ilimitadamente por actos de privados, pero en caso de que tenga conocimiento "de una situación de riesgo real e inmediato para un individuo o grupo de individuos determinado" 16 la ineficacia en su actuar acarrea su responsabilidad internacional. En el caso de Campo Algodonero, México tenía pleno conocimiento de la gravedad, extensión y complejidad de la violencia contra las mujeres en Ciudad Juárez y a juicio de la Corte no (i) adoptó medidas de prevención efectivas que redujeran los factores de riesgo para las mujeres ${ }^{17}$, ni (ii) medidas "razonables, conforme a las circunstancias que rodeaban a los casos, para encontrar a las víctimas con vida"18.

El patrón sistemático y el incumpliendo de la obligación de garantizar también fueron elementos que definieron la responsabilidad internacional del Estado en el "Caso de la Masacre de las Dos Erres":

"140. [...][E]l Tribunal estima que la falta de investigación de hechos graves contra la integridad personal como torturas y violencia sexual en conflictos armados y/o dentro de patrones sistemáticos, constituyen un incumplimiento de las obligaciones del Estado frente a graves violaciones a derechos humanos, las cuales contravienen normas inderogables (jus cogens) y generan obligaciones para los Estados como la de investigar y sancionar dichas prácticas, de conformidad con la Convención Americana y en este caso a la luz de la CIPST y de la Convención de Belém do Pará".

No es la primera vez que la Corte establece la responsabilidad internacional del Estado por actos de privados. Desde el caso Velásquez Rodríguez ${ }^{19}$ la ineficacia en el cumplimiento de la obligación de garantía - prevenir, investigar y sancionar- genera dicha responsabilidad y el deber

14 Ídem. Párr. 286.

15 Para una reflexión sobre los desafíos del sistema penal en la tutela de los derechos de las mujeres ver ARAUJO, Jaime et al. Simposio. Violencia contra las mujeres en el espacio doméstico y la tutela del Estado: desafíos y limitaciones de la respuesta punitiva. Anuario de Derechos Humanos 2009 (5) pp. 61-81.

16 Caso González y otras (“Campo Algodonero”) Vs. México. Párr. 282.

17 ĺdem. Párr. 279.

18 Ídem. Párr. 284.

19 Caso Velásquez Rodríguez Vs. Honduras. Fondo. Sentencia de 29 de julio de 1988. Serie C No. 4. Al efecto ver: MEDINA, Cecilia. La Convención Americana: Teoría y Jurisprudencia. Vida, Integridad Personal, Libertad Personal, Debido Proceso y Recurso Judicial. Centro de Derechos Humanos, Facultad de Derecho, Universidad de Chile. San José, Costa Rica, 2005, pp. 1-57. 
correlativo de reparar. Lo interesante, específicamente del Caso de Campo Algodonero, es que ésta es la primera vez que la Corte aplica este criterio en un caso de violencia contra las mujeres, fenómeno que pocos años atrás no era percibido como un problema de derechos humanos, sino como problemas culturales propios y privados de cada Estado ${ }^{20}$.

Ambas sentencias comparten las deficiencias en el actuar del aparato del Estado. Por una parte, en la identificación de la violencia contra las mujeres como una manifestación extrema de la discriminación que las afecta; y por otra, en la falta de visibilización de la violencia sexual como una forma de violencia de género. Estas sentencias ponen de relieve, elocuentemente, los sesgos y concepciones culturales propias de los operadores judiciales encargados de velar por la erradicación de la violencia contra las mujeres. El desafío para los Estados será, precisamente, dar cabal cumplimiento a las medidas de reparación orientadas a superar estos estereotipos.

La Corte interpreta los artículos 4.1, 5.1, 5.2 y 7.1 de la Convención, considerando que los Estados deben cumplir con las obligaciones de respetar y garantizar el pleno goce de los derechos "sin discriminación alguna por motivos de raza, color, $\underline{\text { sexo, }}$ idioma, religión, opiniones políticas o de cualquier otra índole, origen nacional o social, posición económica, nacimiento o cualquier otra condición social" ${ }^{21}$. Esta cláusula subordinada de igualdad ${ }^{22}$ incorpora la prohibición de discriminación en el goce de los derechos que, en el caso de la violencia de género contra las mujeres, es complementada por las obligaciones específicas que en esta materia establece la Convención de Belém do Pará. En el análisis de casos de violencia contra las mujeres, la prohibición de discriminación en el goce de los derechos y el criterio cualitativo que establece la Corte, requiere realizar un examen de las condiciones culturales que construyen los estereotipos sobre el rol de la mujer en la sociedad. A nuestro juicio, el análisis sobre los estereotipos debiera extenderse a las minorías sexuales que, precisamente por su género, son víctimas de discriminación y violencia ${ }^{23}$.

Finalmente, resulta interesante que la Corte, a pesar de haber encontrado una violación del artículo 5.1 de la Convención, no lo haya hecho respecto del 5.2, que consagra la prohibición absoluta de la tortura y de las penas o tratos crueles, inhumanos o degradantes. Ciertamente, las vejaciones a las que fueron sometidas las víctimas en el caso fueron sufrimientos lo suficientemente graves como para ser calificados como tortura o trato cruel, inhumano o degradante ${ }^{24}$, aun cuando en el caso no haya sido acreditado que fueron hechos cometidos por agentes del Estado o particulares

20 En el 2001 la Comisión Interamericana estableció la responsabilidad internacional del Estado por actos de privados y el incumplimiento de la obligación de garantía en el caso de violencia contra la mujer de Maria Da Penha. Comisión Interamericana de Derechos Humanos. Informe No 54/01. Caso 12.051, Maria Da Penha Maia Fernandes contra Brasil. 16 de abril de 2001.

21 Artículo 1.1. Convención Americana sobre Derechos Humanos. Énfasis añadido.

22 BAYEFSKY, Anne. The Principle of Equality or Non-discrimination in International Law. Human Rights Law Journal. (II) 1-2:1-34, 1990.

23 Si bien la Corte utiliza el patrón sistemático de violencia contra las mujeres en el caso González y otras (Campo Algodonero) Vs. México para establecer la responsabilidad del Estado, lo cierto es que la interpretación que hace de la discriminación estructural basada en los estereotipos que existen en la sociedad sobre un determinado colectivo, ha sido una constante en su jurisprudencia reciente, particularmente en el caso de las personas pertenecientes a comunidades indígenas. Por ejemplo, ver, Caso Comunidad Indígena Yakye Axa Vs. Paraguay. Fondo Reparaciones y Costas. Sentencia 17 de junio de 2005. Serie C No. 125; Caso Comunidad Indígena Sawhoyamaxa Vs. Paraguay. Fondo, Reparaciones y Costas. Sentencia de 29 de marzo de 2006. Serie C No. 146.

24 "[...]la Corte entiende que los elementos constitutivos de la tortura son los siguientes: a) un acto intencional; b) que cause severos sufrimientos físicos o mentales, y c) que se cometa con determinado fin o propósito. [...] al apreciar la severidad del sufrimiento padecido, la Corte debe tomar en cuenta las circunstancias específicas de cada caso, teniendo en cuenta factores endógenos y exógenos. Los primeros se refieren a las características del trato, tales como la duración, el método utilizado o el modo en que fueron infligidos los padecimientos, así como los efectos físicos y mentales que éstos tienden a causar. Los segundos remiten a las condiciones de la persona que padece dichos sufrimientos, entre ellos la edad, el sexo, el estado de salud, así como toda otra circunstancia personal". Corte IDH. Caso Bueno Alves Vs. Argentina. Fondo, Reparaciones y Costas. Sentencia de 11 de mayo de 2007. Serie C No. 164. Párrs. 79 y 83. 
actuando con su aquiescencia o tolerancia. En este sentido, es interesante el voto concurrente de la jueza Cecilia Medina, quien califica como tortura la violencia contra las mujeres cuyos cuerpos fueron encontrados con claras señales de mutilaciones y abusos sexuales en un campo algodonero de Ciudad Juárez ${ }^{25}$.

\section{b. Revisitando la obligación de garantía}

No hay duda alguna de que la obligación de garantía es una construcción compleja en la jurisprudencia de la Corte Interamericana. Es posible observar diferentes facetas de la misma: medidas para asegurar el goce y ejercicio de los derechos; medidas de prevención; medidas de actuación frente a amenazas; obligación de cooperación con instancias internacionales. Pero, difícilmente, habrá un aspecto más problemático de la obligación de garantía que la respuesta estatal frente a las violaciones de derechos humanos, esto es, las medidas de investigación y sanción a los responsables. En su jurisprudencia 2009 la Corte nos vuelve a plantear algunas cuestiones que no es posible dejar de comentar en una reseña de su jurisprudencia.

Hay algunas cuestiones que parecieran claras. En el Caso Ríos ${ }^{26}$ y en el Caso Perozo ${ }^{27}$, se confirma el razonamiento que viene desde la sentencia Velásquez Rodríguez Vs. Honduras, estableciendo que la obligación de investigar violaciones de Derechos Humanos, deriva de la obligación de garantizar dichos derechos. La Corte en dicha primera sentencia contenciosa señaló:

"La obligación general de garantizar los derechos humanos reconocidos en la Convención, contenida en el artículo 1.1, puede ser cumplida de diferentes maneras, en función del derecho específico que el Estado deba garantizar y de las particulares necesidades de protección. Por ello, corresponde determinar si en este caso, y en el contexto en que ocurrieron los hechos alegados, la obligación general de garantía imponía al Estado el deber de investigarlos efectivamente, como medio para garantizar el derecho a la libertad de expresión y a la integridad personal, y evitar que continuaran ocurriendo" 28 .

El razonamiento de la Corte Interamericana parece ser impecable frente a violaciones graves de derechos humanos, tal como las ha entendido la Corte, es decir, violaciones donde se afectan ciertos derechos en forma especialmente severa (torturas sistemáticas, desapariciones forzadas, ejecuciones extrajudiciales $)^{29}$. En estos casos, que la Corte ha asimilado a violaciones masivas y

25 “[8] Si se leen los párrafos 218, 219, 220 y 230 de este fallo, puede advertirse que las tres víctimas sufrieron graves agresiones físicas y muy probablemente violencia sexual de algún tipo antes de su muerte. La descripción del estado de los cadáveres, aunque fue hecha de manera ineficiente en los primeros momentos, muestra la magnitud del tratamiento que se les infligió, de modo que los hechos permitían ser considerados como actos de tortura. [9] No parece pues, haber justificación al hecho de que el tratamiento que se aplicó a las tres víctimas de este caso no se haya calificado como tortura, salvo el hecho de que la Corte consideró que no era posible encontrar que un Estado pudiera ser responsable de un acto de tortura si no había prueba de que éste hubiera sido perpetrado por agentes del Estado o se hubiera Ilevado a cabo cuando un empleado o funcionario público pudiendo impedir el acto no lo hubiera hecho (artículo 3.a8 de la CIPST) o, en los términos del artículo 19 de la Convención contra la Tortura, el acto se hubiera realizado con la aquiescencia de un agente del Estado". Voto concurrente de la Jueza Cecilia Medina Quiroga en relación con la sentencia de la Corte Interamericana de Derechos Humanos en el caso González y Otras ("Campo Algodonero") Vs. México, de 16 de noviembre de 2009, párrs. 8 y 9.

26 Caso Ríos y otros Vs. Venezuela. Excepciones Preliminares, Fondo, Reparaciones y Costas. Sentencia de 28 de enero de 2009. Serie C No. 194. Párr. 282.

27 Caso Perozo y otros Vs. Venezuela. Excepciones Preliminares, Fondo, Reparaciones y Costas. Sentencia de 28 de enero de 2009. Serie C No. 195. Párr. 298.

28 Caso Velásquez Rodríguez. Párr. 177.

29 Ver NASH, Claudio y SARMIENTO, Claudia, Reseña de Jurisprudencia de la Corte Interamericana de Derechos Humanos (2006), en Anuario de Derechos Humanos 2007 (3), Centro de Derechos Humanos, Facultad de Derecho - Universidad de Chile, 2007, pp. 121-129. 
sistemáticas o a crímenes de lesa humanidad, parece evidente que la investigación penal tenga ciertas características particulares que la hacen más estricta: debe ser de motu proprio, no pueden concurrir circunstancias atenuantes ni eximentes de responsabilidad, entre otras.

El problema surge cuando nos enfrentamos a otro tipo de violaciones, que no pueden ser calificadas de "violaciones graves", esto es, que no se dan en un contexto de violaciones masivas o sistemáticas, pero que sí comprometen bienes jurídicos especialmente protegidos a través de la sanción penal. En estos casos, la Corte Interamericana ha tenido que ir aclarando qué es lo que se puede exigir del Estado.

La Corte ha dicho en el Caso Tristán ${ }^{30}$ y en el Caso Kawas ${ }^{31}$ que:

“El deber de investigar es una obligación de medios y no de resultado. Como ha sido señalado por la Corte de manera reiterada, este deber ha de ser asumido por el Estado como un deber jurídico propio y no como una simple formalidad condenada de antemano a ser infructuosa, o como una mera gestión de intereses particulares, que dependa de la iniciativa procesal de las víctimas o de sus familiares o de la aportación privada de elementos probatorios" ${ }^{\prime 2}$.

En cuanto a la regulación procesal de la acción penal, la Corte estableció en el Caso Ríos ${ }^{33}$ y en el Caso Perozo ${ }^{34}$ lo siguiente:

"La obligación de investigar 'no sólo se desprende de las normas convencionales de Derecho Internacional imperativas para los Estados Parte, sino que además se deriva de la legislación interna que haga referencia al deber de investigar de oficio ciertas conductas ilícitas'. Así, corresponde a los Estados Parte disponer, de acuerdo con los procedimientos y a través de los órganos establecidos en su Constitución y sus leyes, qué conductas ilícitas serán investigadas de oficio y regular el régimen de la acción penal en el procedimiento interno, así como las normas que permitan que los ofendidos o perjudicados denuncien o ejerzan la acción penal y, en su caso, participen en la investigación y en el proceso" 35 .

La Corte reconoce la libertad con que cuentan los Estados para ordenar su sistema procesal, sin embargo, si estos párrafos se leen en concordancia con lo establecido en los casos Kawas ${ }^{36}$, Ríos $^{37}$ y Perozo ${ }^{38}$, se llega a la conclusión que a lo menos las violaciones más graves deben ser investigadas de oficio, por tanto el Estado no goza de libertad plena en este sentido.

En cuanto a la actividad investigadora del Estado, en el Caso Kawas ${ }^{39}$, la Corte recoge una jurisprudencia citada en el Caso Juan Humberto Sánchez ${ }^{40}$, sobre los criterios que deben regir cuando es el Derecho a la Vida el derecho afectado, señala:

30 Caso Tristán Donoso Vs. Panamá. Excepción Preliminar, Fondo, Reparaciones y Costas. Sentencia de 27 de enero de 2009. Serie C No. 193. Párr. 146.

31 Caso Kawas Fernández Vs. Honduras. Fondo, Reparaciones y Costas. Sentencia de 3 de abril de 2009. Serie C. No. 196. Párr. 101.

32 Caso Tristán. Párr. 146.

33 Caso Ríos. Párr. 284.

34 Caso Perozo. Párr. 299.

35 Caso Ríos y Caso Perozo. Párrs. 285 y 299, respectivamente.

36 Caso Kawas. Párr. 75.

37 Caso Ríos y Caso Perozo. Párrs. 285 y 299, respectivamente.

38 Caso Perozo. Párr. 298.

39 Caso Kawas. Párr. 102.

40 Sentencia de 7 de junio de 2003. Excepción Preliminar, Fondo, Reparaciones y Costas. Serie C No. 99. 
"Esta Corte ha especificado los principios rectores que es preciso observar en una investigación cuando se está frente a una muerte violenta. Conforme a la jurisprudencia de la Corte Interamericana, las autoridades estatales que conducen una investigación de este tipo deben intentar como mínimo, inter alia: a) identificar a la víctima; b) recuperar y preservar el material probatorio relacionado con la muerte, con el fin de ayudar en cualquier potencial investigación penal de los responsables; c) identificar posibles testigos y obtener sus declaraciones en relación con la muerte que se investiga; d) determinar la causa, forma, lugar y momento de la muerte, así como cualquier patrón o práctica que pueda haber causado la muerte, y e) distinguir entre muerte natural, muerte accidental, suicidio y homicidio. Además, es necesario investigar exhaustivamente la escena del crimen, se deben realizar autopsias y análisis de restos humanos, en forma rigurosa, por profesionales competentes y empleando los procedimientos más apropiados" ${ }^{\prime 1}$.

Se podrá concordar que la Corte aporta dos elementos relevantes: por una parte, determina que ciertas afectaciones a bienes jurídicos tutelados por la Convención Americana -independiente del contexto en que se produzcan dichas violaciones- ameritan una acción investigativa del Estado independiente de la actividad de las víctimas o sus familiares. Segundo, que la investigación que lleve adelante el Estado deberá responder a ciertos mínimos que buscan garantizar que dicha investigación sea seria y conduzca efectivamente a los resultados esperados. Por tanto, lo que parece diferenciar a estos casos de otros calificados como "violaciones graves" dice relación con la posibilidad de aplicar medidas que mitiguen la responsabilidad, como amnistías, prescripciones y otras.

\section{Análisis de derechos}

\section{a. Derecho a la vida y sus proyecciones}

El artículo 4 de la Convención consagra la prohibición de privación arbitraria de la vida. En el Caso Dacosta Cadogan Vs. Barbados ${ }^{42}$ la Corte reiteró su criterio en relación a la pena de muerte, indicando que:

"[E]l artículo 4.2 de la Convención permite la privación del derecho a la vida por medio de la imposición de la pena de muerte en aquellos Estados en los que no ha sido abolida. Esto es, que la pena de muerte no es per se incompatible o prohibida por la Convención Americana. Sin embargo, la Convención ha establecido una serie de limitaciones estrictas a la imposición de la pena de muerte. Primero, la imposición de la pena de muerte debe limitarse a los delitos comunes más graves no relacionados con los delitos políticos. Segundo, la pena debe ser individualizada según las características del delito, la participación del acusado y su grado de culpabilidad. Por último, la imposición de esta sanción está sujeta a ciertas garantías procesales y el cumplimiento de las mismas debe ser estrictamente observado y revisado" 43 .

La Corte indicó que la imposición obligatoria de la pena de muerte es incompatible con las estrictas limitaciones que la Convención Americana establece para su procedencia, particularmente, con la prohibición de privación arbitraria de la vida y (o "arbitrariamente") su imposición como sanción para los delitos más graves ${ }^{44}$. Indicó también que las disposiciones de la Convención respecto de la aplicación de la pena de muerte deben interpretarse a la luz del principio pro persona, el cual

41 Caso Humberto Sánchez. Párr. 127.

42 Corte IDH. Caso Dacosta Cadogan Vs. Barbados. Excepciones Preliminares, Fondo, Reparaciones y Costas. Sentencia de 24 de septiembre de 2009. Serie C No. 204.

43 Caso Dacosta Cadogan Vs. Barbados. Párr. 47.

44 Ídem. Párr. 48. 
impone "restricciones para limitar rigurosamente la aplicación y alcance [de la pena de muerte], de modo que se vaya reduciendo hasta su supresión final" 45 .

El criterio constante ${ }^{46}$ de la Corte respecto de la pena de muerte y la extensión del derecho a la vida tiene interesantes consecuencias. Por una parte, la Corte señala que lo prohibido es la privación "arbitraria" de la vida, dejando a salvo la posibilidad de la legislación de regular supuestos de privación de la vida que no comprometan la responsabilidad internacional de los Estados. El ejemplo que la propia Corte utiliza es el de la legítima defensa, pero ciertamente este criterio puede ser utilizado, por ejemplo, en la discusión sobre el aborto por indicaciones médicas o aborto terapéutico en la región. Particularmente, cuando la penalización del aborto terapéutico se funda en una premisa de protección absoluta de la vida del que está por nacer, la decisión de la Corte en el caso Dacosta sienta un precedente: el derecho a la vida admite limitaciones. Estas limitaciones muy probablemente deban ser analizadas conforme con los requisitos que la Convención Americana ha establecido y los criterios que la Corte ha construido para justificar la restricción de los derechos de este tratado.

Por otra, si las mujeres titulares del derecho a la vida ven restringido o vulnerado su derecho por la prohibición de interrumpir el embarazo, es necesario analizar si dicha acción del Estado puede ser considerada una restricción legítima al derecho, o bien una privación arbitraria de su derecho a la vida.

\section{b. Derecho al debido proceso: independencia judicial}

En el ámbito del debido proceso, una cuestión central es establecer las características del órgano encargado de determinar los derechos u obligaciones, así como de resolver una eventual acusación penal. Dentro de las características que debe reunir dicho órgano, la independencia judicial ha concentrado la atención de la Corte durante el 2009. Reseñaremos brevemente los principales aportes de la Corte en esta materia ${ }^{47}$.

En el caso Reverón Trujillo ${ }^{48}$, la Corte Interamericana sintetiza lo expuesto en fallos anteriores respecto del principio de independencia judicial, señalando que:

“(...) El Tribunal ha dicho que uno de los objetivos principales que tiene la separación de los poderes públicos es la garantía de la independencia de los jueces. Dicho ejercicio autónomo debe ser garantizado por el Estado tanto en su faceta institucional, esto es, en relación con el Poder Judicial como sistema, así como también en conexión con su vertiente individual, es decir, con relación a la persona del juez específico. El objetivo de la protección radica en evitar que el sistema judicial en general y sus integrantes en particular se vean sometidos a posibles restricciones indebidas en el ejercicio de su función por parte de órganos ajenos al Poder Judicial o incluso por parte de aquellos magistrados que ejercen funciones de revisión o apelación. Adicionalmente, el Estado está en el deber de garantizar una apariencia de independencia de la magistratura que inspire legitimidad y confianza suficiente no sólo al justiciable, sino a los ciudadanos en una sociedad democrática" ${ }^{\prime 9}$.

\footnotetext{
45 Ídem. Párr. 49.

46 Además del caso Dactosta, ver: Corte IDH. Caso Boyce y otros Vs. Barbados. Excepción Preliminar, Fondo, Reparaciones y Costas. Sentencia de 20 de noviembre de 2007. Serie C No. 169.

47 Para una versión ampliada de este tema, ver Boletín Trimestral con Jurisprudencia de la Corte Interamericana, Centro de Derechos Humanos de la Universidad de Chile, No 2, 2009, pp. 6-8.

48 Caso Reverón Trujillo Vs. Venezuela. Excepción Preliminar, Fondo, Reparaciones y Costas. Sentencia de 30 de junio de 2009. Serie C No. 197.

49 Caso Reverón Trujillo. Párr. 67.
} 
La Corte Interamericana reafirma, además, la vigencia del principio de independencia judicial en todas las fases del proceso y bajo toda circunstancia, señalando:

"El principio de independencia judicial (...) debe ser respetado en todas las áreas del procedimiento y ante todas las instancias procesales en que se decide sobre los derechos de la persona (...) Su alcance debe garantizarse inclusive, en situaciones especiales, como lo es el estado de excepción"50.

Asegurar un tribunal verdaderamente independiente supone resguardar eficazmente ciertos elementos relativos a la organización y funcionamiento de quienes ejercen labores jurisdiccionales. La Corte Interamericana sistematiza dichos elementos en tres garantías:

"Conforme a la jurisprudencia de esta Corte y de la Corte Europea, así como de conformidad con los Principios Básicos de las Naciones Unidas relativos a la independencia de la judicatura (en adelante "Principios Básicos"), las siguientes garantías se derivan de la independencia judicial: un adecuado proceso de nombramiento, la inamovilidad en el cargo y la garantía contra presiones externas" 51 .

En el caso Reverón Trujillo, la Corte analiza la importancia e implicancias de lo que considera la primera garantía derivada de la independencia judicial: los jueces deben ser escogidos mediante un "adecuado proceso de nombramiento":

"[...] La Corte destaca que todo proceso de nombramiento debe tener como función no sólo la escogencia según los méritos y calidades del aspirante, sino el aseguramiento de la igualdad de oportunidades en el acceso al Poder Judicial. En consecuencia, se debe seleccionar a los jueces exclusivamente por el mérito personal y su capacidad profesional, a través de mecanismos objetivos de selección y permanencia que tengan en cuenta la singularidad y especificidad de las funciones que se van a desempeñar" 52 .

"[...] No cualquier procedimiento satisface las condiciones que exige la Convención para la implementación adecuada de un verdadero régimen independiente. Si no se respetan parámetros básicos de objetividad y razonabilidad, resultaría posible diseñar un régimen que permita un alto grado de discrecionalidad en la selección del personal judicial de carrera, en virtud de lo cual las personas escogidas no serían, necesariamente, las más idóneas" ${ }^{\prime 23}$.

Una segunda garantía que deriva de la independencia judicial, es aquella conocida como "principio de inamovilidad":

"Los Principios Básicos establecen que ' [l]a ley garantizará la permanencia en el cargo de los jueces por los períodos establecidos' y que [s] garantizará la inamovilidad de los jueces (...) hasta que cumplan la edad para la jubilación forzosa o expire el período para el que hayan sido nombrados o elegidos, cuando existan normas al respecto" ${ }^{\prime 24}$.

"Finalmente, los Principios Básicos establecen que los jueces 'sólo podrán ser suspendidos o separados de sus cargos por incapacidad o comportamiento que los inhabilite para seguir desempeñando sus funciones' y que '[t]odo procedimiento para la adopción de medidas disciplinarias, la suspensión o la separación del cargo se resolverá de acuerdo con las normas establecidas de comportamiento judicial'. De manera similar, el Comité de Derechos Humanos ha señalado que

50 Ídem. Párr. 68.

51 Ídem. Párr. 70.

52 Ídem. Párr. 72.

53 Ídem. Párr. 74.

54 Ídem. Párr. 75. 
los jueces sólo pueden ser removidos por faltas de disciplina graves o incompetencia y acorde a procedimientos justos que aseguren la objetividad e imparcialidad según la constitución o la ley. Además, el Comité ha expresado que '[l]a destitución de jueces por el [P]oder [E]jecutivo antes de la expiración del mandato para el que fueron nombrados, sin que se les dé ninguna razón concreta y sin que dispongan de una protección judicial efectiva para impugnar la destitución, es incompatible con la independencia judicial'" ${ }^{\prime \prime 55}$.

Según lo visto, la Corte Interamericana desprende del principio de independencia judicial tres garantías, una de las cuales corresponde al principio de inamovilidad. Pero a su vez, a partir de este principio de inamovilidad, la Corte deriva tres garantías más:

"De todo esto se puede concluir que la inamovilidad es una garantía de la independencia judicial que a su vez está compuesta por las siguientes garantías: permanencia en el cargo, un proceso de ascensos adecuado y no despido injustificado o libre remoción. Quiere decir esto que si el Estado incumple una de estas garantías, afecta la inamovilidad y, por tanto, no está cumpliendo con su obligación de garantizar la independencia judicial" ${ }^{56}$.

La tercera y última garantía de la Independencia Judicial se refiere a la garantía contra presiones externas:

“Los Principios Básicos disponen que los jueces resolverán los asuntos que conozcan "basándose en los hechos y en consonancia con el derecho, sin restricción alguna y sin influencias, alicientes, presiones, amenazas o intromisiones indebidas, sean directas o indirectas, de cualesquiera sectores o por cualquier motivo[...] $]^{\prime \prime 57}$.

Como es posible observar la Corte va construyendo una idea compleja del requisito de independencia judicial que va más allá de una simple ausencia de interferencias de otros poderes del Estado, para construir un principio con implicancias tanto externas como internas a la administración.

\section{c. Derechos políticos}

Cuando nos plateamos la pregunta sobre el alcance de los derechos políticos en la Convención Americana, lo que se nos viene a la cabeza dice relación con el derecho a elegir y ser elegido, la continuidad del proceso democrático, las formas de elección y participación políticas. En su jurisprudencia 2009 la Corte ha innovado en este acercamiento y ha planteado la idea de que la garantía de los derechos políticos también comprende la estabilidad en el cargo público al que se accede. Además, establece que ciertos cargos pueden justificar una garantía reforzada de estabilidad, atendido su efecto en otros derechos ${ }^{58}$.

En efecto, en el caso Reverón Trujillo, la Corte comienza refiriéndose brevemente a la condición de funcionarios públicos de los jueces y a la necesaria estabilidad de sus cargos, para luego examinar ciertas garantías "reforzadas" que aquellos ostentan y que emanan ya no de su carrera funcionaria, sino del principio de independencia judicial:

"Los jueces que forman parte de la carrera judicial cuentan, en primer lugar, con la estabilidad que brinda el ser funcionario de carrera. El principio general en materia laboral para los trabajadores

55 Ídem. Párr. 77.

56 Ídem. Párr. 79.

57 Ídem. Párr. 80.

58 Boletín Trimestral con Jurisprudencia de la Corte Interamericana, Centro de Derechos Humanos de la Universidad de Chile, No2, 2009, p. 12. 
públicos de carrera es la estabilidad[...] Mientras de su parte haya observancia de las condiciones fijadas por la ley en relación con su desempeño, no será removido" ${ }^{\prime 59}$.

"Ahora bien, los jueces, a diferencia de los demás funcionarios públicos, cuentan con garantías reforzadas debido a la independencia necesaria del Poder Judicial[...]"60.

Se enuncia así una interesante conexión entre el derecho a un tribunal independiente (artículo 8) y el derecho de acceso igualitario a la función pública (artículo 23$)^{61}$ en vista que la Corte -siguiendo al Comité de Derechos Humanos- entiende que este último derecho comprende la protección de la permanencia en el cargo público al que se accede. Al respecto, la Corte concluye que la permanencia de un juez en su cargo constituye una garantía inherente al derecho de acceso igualitario a la función pública:

“(...) La Corte resalta que en el caso Apitz Barbera y otros, este Tribunal precisó que el artículo 23.1.c no establece el derecho a acceder a un cargo público, sino a hacerlo en 'condiciones generales de igualdad'. Esto quiere decir que el respeto y garantía de este derecho se cumplen cuando 'los criterios y procedimientos para el nombramiento, ascenso, suspensión y destitución [sean] razonables y objetivos' y que 'las personas no sean objeto de discriminación' en el ejercicio de este derecho. Asimismo, el Comité de Derechos Humanos ha interpretado que la garantía de protección abarca tanto el acceso como la permanencia en condiciones de igualdad y no discriminación respecto a los procedimientos de suspensión y destitución. Como se observa, el acceso en condiciones de igualdad constituiría una garantía insuficiente si no está acompañado por la protección efectiva de la permanencia en aquello a lo que se accede" 62 .

Resulta destacable que tanto la permanencia de los jueces en la función pública, sin discriminación, así como las garantías incluidas en el principio de independencia judicial, convergen en la exigencia de procedimientos y criterios objetivos y razonables para el nombramiento, ascenso, suspensión y destitución de aquellos. Esto importa, en otras palabras, que el artículo 23 y el artículo 8.1 de la Convención coinciden en reclamar del Estado ciertos estándares mínimos al definir la organización del Poder Judicial.

\section{d. Derechos económicos, sociales y culturales (DESC)}

El capítulo III de la Convención Americana consagra en su artículo único (26) el deber de desarrollo progresivo de los derechos económicos, sociales y culturales. Hasta ahora, la Corte no ha establecido una violación del artículo 26 en un caso contencioso, pero en los casos Acevedo Buendía y Otros Vs. Perú y Caso Kawas Fernández Vs. Honduras, otorga elementos sobre cuál es el contenido y extensión de este derecho y de las obligaciones del Estado, y cómo ello se relaciona con el medio ambiente.

59 Ídem. Párr. 64.

60 Ídem. Párr. 67.

61 Artículo 23. Derechos Políticos. 1. Todos los ciudadanos deben gozar de los siguientes derechos y oportunidades: (a) de participar en la dirección de los asuntos públicos, directamente o por medio de representantes libremente elegidos; (b) de votar y ser elegidos en elecciones periódicas auténticas, realizadas por sufragio universal e igual y por voto secreto que garantice la libre expresión de la voluntad de los electores, y (c) de tener acceso, en condiciones generales de igualdad, a las funciones públicas de su país. 2. La ley puede reglamentar el ejercicio de los derechos y oportunidades a que se refiere el inciso anterior, exclusivamente por razones de edad, nacionalidad, residencia, idioma, instrucción, capacidad civil o mental, o condena, por juez competente, en proceso penal.

62 Caso Reverón Trujillo. Párr. 138. 
En el caso Acevedo la Corte no se refirió a la exigibilidad del derecho a la seguridad social ${ }^{63}$, pues la discusión se centró en el incumplimiento de las decisiones judiciales de tribunales internos de Perú y la correlativa afectación al derecho de propiedad de los peticionarios ${ }^{64}$. Es decir, la Corte no analizó si la disminución de las pensiones constituía una medida regresiva, contraria al deber de desarrollo progresivo de los derechos económicos, sociales y culturales contenido en el artículo 26 de la Convención Americana ${ }^{65}$. A pesar de no encontrar una violación, la Corte señaló que el desarrollo progresivo de los derechos económicos, sociales y culturales "no siempre deberá ser entendido como una prohibición de medidas que restrinjan el ejercicio de un derecho". Citando al Comité de Derechos Económicos, Sociales y Culturales de las Naciones Unidas y a la Comisión Interamericana, indicó que una medida regresiva deberá justificarse con razones de peso y que "la regresividad resulta justiciable cuando de derechos económicos, sociales y culturales se trate" ${ }^{\prime \prime 6}$.

En el Caso Kawas la Corte reafirmó lo señalado en casos anteriores acerca de la universalidad, indivisibilidad e interdependencia de los derechos civiles y políticos y los derechos económicos, sociales y culturales, y cómo el goce de éstos se relaciona con el medio ambiente. Al efecto señaló que:

"148. Además, como se desprende de la jurisprudencia de este Tribunal y de la Corte Europea de Derechos Humanos, existe una relación innegable entre la protección del medio ambiente y la realización de otros derechos humanos. Las formas en que la degradación ambiental y los efectos adversos del cambio climático han afectado al goce efectivo de los derechos humanos en el continente ha sido objeto de discusión por parte de la Asamblea General de la Organización de los Estados Americanos y las Naciones Unidas. También se advierte que un número considerable de Estados partes de la Convención Americana ha adoptado disposiciones constitucionales reconociendo expresamente el derecho a un medio ambiente sano. Estos avances en el desarrollo de los derechos humanos en el continente han sido recogidos en el Protocolo Adicional a la Convención Americana sobre Derechos Humanos en materia de Derechos Económicos, Sociales y Culturales Protocolo de San Salvador".

Si bien en el caso Acevedo la Corte no analiza la medida de restricción de las pensiones como una medida regresiva, es clara en señalar que una acción de este tipo sería justiciable. Esto abre las puertas hacia la revisión de políticas públicas que disminuyan el pleno goce, entre otros, del derecho a la salud, la educación o los derechos sindicales, no sólo a través de la interpretación amplia de los derechos civiles y políticos, sino directamente. Si las medidas de restricción deben obedecer a razones de peso, cabe preguntarse si la Corte seguirá alguno de los patrones que ha establecido en el caso de la restricción de los derechos civiles y políticos, por ejemplo, el ser una medida "necesaria en una sociedad democrática", y si aplicará el límite a la interpretación contenido en el artículo 29 de la Convención Americana.

63 Corte IDH. Caso Acevedo Jaramillo y otros Vs. Perú. Excepciones Preliminares, Fondo, Reparaciones y Costas. Sentencia de 7 de febrero de 2006. Serie C No. 144. Párr. 52.

64 Caso Acevedo Jaramillo y otros Vs. Perú. Párrs. 80, 85, 88 y 106.

65 Capítulo III, Derechos Económicos, Sociales y Culturales. Artículo 26. Desarrollo Progresivo. Los Estados partes se comprometen a adoptar providencias, tanto a nivel interno como mediante la cooperación internacional, especialmente económica y técnica, para lograr progresivamente la plena efectividad de los derechos que se derivan de las normas económicas, sociales y sobre educación, ciencia y cultura, contenidas en la Carta de la Organización de los Estados Americanos, reformada por el Protocolo de Buenos Aires, en la medida de los recursos disponibles, por vía legislativa $\mathrm{u}$ otros medios apropiados.

66 Caso Acevedo Jaramillo y otros Vs. Perú. Párr. 103. 
La relación del medio ambiente con los derechos humanos ya había sido abordada por la Corte cuando analizó el vínculo de los pueblos indígenas con su territorio y los elementos que lo componen. No obstante, queda pendiente dilucidar si la relación entre el medio ambiente y los derechos humanos seguirá la lógica que hasta ahora ha tenido en la jurisprudencia de la Corte la relación de los derechos económicos, sociales y culturales con los civiles y políticos: una interpretación amplia de los segundos y no una justiciabilidad directa de los primeros. Ya sea que la Corte resuelva utilizando una interpretación amplia de los derechos civiles y políticos, o bien analice la justificación de una medida regresiva contraria al deber de desarrollo progresivo del artículo 26 de la Convención, es factible que pueda resolver un caso donde los derechos humanos de las personas se vean afectados por alteraciones al medio ambiente, por ejemplo, en proyectos que afecten recursos naturales como el agua, el aire o la tierra. 